\title{
Modulation of the metastatic progression of breast cancer with an organometallic ruthenium compound
}

\author{
ALBERTA BERGAMO $^{1}$, ALESSIA MASI ${ }^{1}$, PAUL J. DYSON ${ }^{2}$ and GIANNI SAVA ${ }^{1,3}$ \\ ${ }^{1}$ Callerio Foundation Onlus, Via A. Fleming 22-31, 34127 Trieste, Italy; ${ }^{2}$ Institut des Sciences et \\ Ingénierie Chimiques, Ecole Polytechnique Fédérale de Lausanne (EPFL), CH-1015 Lausanne, Switzerland; \\ ${ }^{3}$ Dipartimento di Scienze Biomediche, Università degli Studi di Trieste, Via L. Giorgieri 7-9, 34127 Trieste, Italy
}

Received July 7, 2008; Accepted September 9, 2008

DOI: 10.3892/ijo_00000119

\begin{abstract}
The modulation of the metastatic progression of breast cancer has been evaluated in vitro and in vivo with RAPTA-T, $\left[\mathrm{Ru}\left(\eta^{6}\right.\right.$-toluene) $\mathrm{Cl}_{2}$ (PTA)], an organometallic ruthenium compound. In vitro RAPTA-T inhibits some steps of the metastatic process such as the detachment from the primary tumour, the migration/invasion and the re-adhesion to a new growth substrate. All these effects are boosted when cells grow on components of the extra cellular matrix such as collagen IV and fibronectin and minimized on the non-specific substrate poly-L-lysine and are more pronounced when experiments are performed with the highly invasive MDAMB-231 cells than with the non-invasive MCF-7 or the nontumourigenic HBL-100. In vivo RAPTA-T selectively reduces the growth of lung metastases, an effect that might be explained by the in vitro activity. The effect on tests requiring the interaction of the tumour cells with extra cellular matrix components, might suggest an interaction with cell surface molecules in the activity of this ruthenium compound.
\end{abstract}

\section{Introduction}

In cancer chemotherapy, research on platinum-based compounds was stimulated by the serendipitous discovery of cisplatin and by its enormous impact in the treatment of several cancer types (1). Previously, the development of different metal compounds has been facilitated by the rich coordination chemistry and redox properties of metal ions and driven by the necessity to fill the unmet needs of chemotherapy, in particular to minimise undesirable sideeffects, to overcome drug resistance and to enlarge the

Correspondence to: Dr Alberta Bergamo, Callerio Foundation Onlus, Via A. Fleming 22-31, 34127 Trieste, Italy

E-mail: a.bergamo@callerio.org

Key words: metastasis, breast cancer, ruthenium, organometallics spectrum of activity to more tumour types and to metastatic (secondary) cancers (2). Notably, ruthenium complexes have been found to be effective against cancers that cannot be treated with platinum drugs and it was also found that they exhibit a lower general toxicity compared to platinum compounds (3-5). Among them, imidazolium trans-imidazoledimethylsulfoxide-tetrachlororuthenate, NAMI-A, shows high and peculiar selectivity for solid tumour metastases and low toxicity at pharmacologically active doses (6) and has successfully completed phase I clinical trials (7). NAMI-A metastasis control is associated with a series of biological activities that influence cell function such as adhesion, motility and invasion $(8,9)$.

Previously, increasing interest has focused on organometallic compounds, specifically on ruthenium(II)-arene compounds which show excellent antiproliferative properties in vitro and in vivo, also in cisplatin-resistant cell lines (10). Our attention has focused on ruthenium(II)-arene complexes combined with the 1,3,5-triaza-7-phosphaadamantane (PTA) ligand. The prototype $\left[\mathrm{Ru}\left(\eta^{6}-\mathrm{p}\right.\right.$-cymene $\left.) \mathrm{Cl}_{2}(\mathrm{PTA})\right]$, termed RAPTA-C (Fig. 1), was found to exhibit pH-dependent DNA damage: at the $\mathrm{pH}$ typical of hypoxic tumour cells DNA was damaged, whereas at the $\mathrm{pH}$ characteristic of healthy cells, little or no damage was detected $(11,12)$. Several structurally diverse RAPTA derivatives have been studied and their in vitro cytotoxicity has been evaluated $(13,14)$. The in vivo effect on the growth of lung metastases was also established for RAPTA-C and RAPTA-B, i.e. [Ru( $\eta^{6}$-benzene $) \mathrm{Cl}_{2}$ (PTA)] (14). In vivo RAPTA-C shows diverse behaviour depending on the schedule of administration: it was found to reduce the number of lung metastases when a cumulative dose of $400 \mathrm{mg} / \mathrm{kg}$ is given fractionated in 2 or 4 treatments. Notably, $200 \mathrm{mg} / \mathrm{kg} /$ day on days 5 and 9 after primary tumour implant, appear to be the most efficient in reducing lung metastases formation. RAPTA-B, in the same experimental mouse model, administrated with a total dose of $400 \mathrm{mg} / \mathrm{kg}$ at two different frequencies has the same effect on the metastases number. Moreover, both RAPTA-C and RAPTA-B do not influence the evolution of growth of the primary tumour.

From a structural and chemical viewpoint NAMI-A and RAPTAs are very different compounds, albeit based on ruthenium. Their oxidation states differ as do their ligand sets, RAPTAs being organometallics and NAMI-A a traditional 
coordination compound. In any case, the anti-metastatic activity of NAMI-A, RAPTA-B and RAPTA-C is unique although NAMI-A is considerably more potent than the two RAPTA compounds. Nevertheless, the signals of activity on metastases of the RAPTA family of compounds suggest the need to known more about their ability to interact with this important phenomenon of cancer growth as current approaches in clinical cancer therapy of most solid tumours have only limited success. Despite earlier tumour detection and better therapeutic regimens having brought significant advances, the presence of metastases remains the most significant poor prognostic factor implying a shortened survival and reduced quality of life. Effective novel therapeutic strategies targeting selectively metastasis development and growth should provide the greatest clinical benefit and RAPTA compounds offer potential as they can easily be systematically modified to exhibit desirable physical, chemical and biological properties.

We studied the effects of RAPTA-T in a series of experiments that simulate in vitro the main steps of the metastatic progression, i.e. the detachment from the primary tumour, the degradation of the extracellular matrix, the ability to migrate, to invade and to adhere to a new organ, comparing the behaviour of MDA-MB-231 highly invasive breast cancer cells to that of MCF-7, tumourigenic but not invasive and of HBL-100 non-tumourigenic mammary epithelial cells. The in vitro behaviour is then compared with the in vivo antimetastatic efficacy of the compound in a mouse experimental model. RAPTA-T was selected for this study despite being unproven in vivo, since it showed in vitro the greatest selectivity towards cancer cells compared to non-tumourigenic cells (14).

\section{Materials and methods}

Materials. RAPTA-T was prepared according to the published procedure (14). All reagents were purchased from SigmaAldrich (St. Louis, MO) unless otherwise indicated.

Tumour cell lines for in vitro tests. The MDA-MB-231 human highly invasive breast cancer cell line was kindly supplied by Dr P. Spessotto (Cro, Aviano, Italy) and maintained in Dulbecco's modified Eagle's medium (EuroClone ${ }^{\circledR}$, Devon, UK) supplemented with $10 \%$ FBS (Gibco, Invitrogen ${ }^{\mathrm{TM}}$, Paisley, Scotland, UK), 2 mM L-glutamine (EuroClone), $1 \%$ nonessential amino acids and $100 \mathrm{IU} / \mathrm{ml}$ penicillin and $100 \mu \mathrm{g} / \mathrm{ml}$ streptomycin (EuroClone).

The MCF-7 human breast cancer cell line was obtained from the American Type Culture Collection (Manassas, VA; catolog number HTB-22) and maintained in Dulbecco's modified Eagle's medium/F12 medium 1:1 v/v (EuroClone) supplemented with $10 \%$ FBS, 2 mM L-glutamine and 100 IU/ $\mathrm{ml}$ penicillin and $100 \mu \mathrm{g} / \mathrm{ml}$ streptomycin .

The HBL-100 human non-tumourigenic epithelial cell line was kindly supplied by Dr G. Decorti (Department of Biomedical Sciences, University of Trieste, Italy) and maintained in McCoy's 5A medium supplemented with 10\% FBS, $2 \mathrm{mM}$ L-glutamine and $100 \mathrm{IU} / \mathrm{ml}$ penicillin and $100 \mu \mathrm{g} / \mathrm{ml}$ streptomycin.

All cell lines were kept in a $\mathrm{CO}_{2}$ incubator with $5 \% \mathrm{CO}_{2}$ and $100 \%$ relative humidity at $37^{\circ} \mathrm{C}$. Cells from a confluent
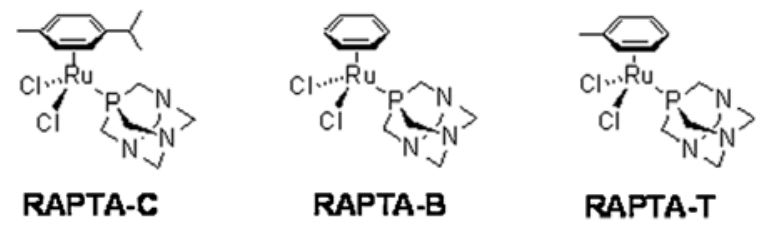

Figure 1. Structure of the ruthenium(II)-arene PTA (RAPTA) compounds.

monolayer were removed from flasks by a trypsin-EDTA solution. Cell viability was determined by the trypan blue dye exclusion test. For experimental purposes cells were sown in multiwell culture clusters.

Resistance to detachment assay. The ability of cells to resist detachment after treatment with RAPTA-T was measured as follows: 96-well plastic plates (Corning Costar, Milano, Italy) were coated with the following substrates: $10 \mu \mathrm{g} / \mathrm{ml}$ polylysine, $20 \mu \mathrm{g} / \mathrm{ml}$ fibronectin from human plasma and $20 \mu \mathrm{g} / \mathrm{ml}$ collagen IV from human placenta and left in a humidified cell culture chamber at $37^{\circ} \mathrm{C}$ for $4 \mathrm{~h}$. Before cell seeding, plates were washed with CMF-DPBS (Calcium and Magnesium Free Dulbecco's phosphate-buffered saline), then $6 \times 10^{3}$ cells in $0.2 \mathrm{ml}$ complete medium were sown in each well. After 2 days at $37^{\circ} \mathrm{C}$, complete medium was replaced with serum-starved medium, containing $0.1 \% \mathrm{w} / \mathrm{v}$ BSA. After $24 \mathrm{~h}$, the medium was removed and the plates washed with CMF-DPBS, before the treatment with RAPTA-T $10^{-4} \mathrm{M}$, dissolved in DPBS (Dulbecco's phosphate-buffered saline), was added to the wells and incubated for $1 \mathrm{~h}$. At the end of the treatment the RAPTA-T containing solution was removed, the plates were washed twice with CMF-DPBS and trypsin solution, $0.008 \% \mathrm{w} / \mathrm{v}$, was added to each well. Plates were kept in agitation for $30 \mathrm{~min}$ at room temperature then trypsin solution was removed and wells washed with CMF-DPBS. Cells that still adherent to the plates were detected by the sulforhodamine B (SRB) test. Resistance to detachment is expressed as arbitrary units, calculated by dividing the mean absorbance of treated cells by the mean absorbance of control cells.

Re-adhesion assay. The effect of the ability of the cells to re-adhere after RAPTA-T treatment, was studied in cells maintained for $24 \mathrm{~h}$ in serum-starved medium and then treated for $1 \mathrm{~h}$ with RAPTA-T $10^{-4} \mathrm{M}$ in DPBS. At the end of the treatment cells were removed from flasks by a trypsinEDTA solution, collected by centrifugation, re-suspended in serum-starved medium supplemented with $0.1 \% \mathrm{w} / \mathrm{v}$ BSA and kept for $30 \mathrm{~min}$ at room temperature to allow surface receptor reconstitution. The cells were then seeded at a density of $1 \times 10^{4}$ cells in $0.1 \mathrm{ml} /$ well on 96 -well plastic plates previously coated as described above with polylysine, fibronectin, collagen IV or $20 \mu \mathrm{g} / \mathrm{ml}$ Matrige $^{\circledR}$ (BD, Biosciences, San Josè, CA). Cells were left to adhere for 30 and 60 min at $37^{\circ} \mathrm{C}$ with $5 \% \mathrm{CO}_{2}$ and $100 \%$ relative humidity, then the medium containing the non-adherent cells was removed and wells were gently washed with CMF-DPBS. Cells that in 30 or $60 \mathrm{~min}$ have adhered to the substrates were detected by the sulforhodamine B (SRB) test. 
Sulforhodamine B assay. Adherent cells were detected with the SRB test described by Skehan et al (15). Briefly, adherent cells were fixed with $10 \% \mathrm{v} / \mathrm{v}$ cold trichloroacetic acid (TCA) at $4^{\circ} \mathrm{C}$ for $1 \mathrm{~h}$. After fixation TCA was discarded and wells washed five times with distilled water and airdried. SRB solution $(0.4 \%, \mathrm{w} / \mathrm{v}$, in $1 \%$ acetic acid) was added to the wells and plates were kept for $30 \mathrm{~min}$ at room temperature. Unbound SRB was removed by washing three times with $1 \%$ acetic acid. Plates were air dried, then bound stain was dissolved with un-buffered $10 \mathrm{mM}$ Tris base (tris-hydroxymethyl-aminomethane) at $\mathrm{pH} 10.5$ and the optical density was read at $570 \mathrm{~nm}$ with an automatic computerised spectrophotometer (SpectraCount; Packard, Meriden, CT).

Migration assays. Migratory ability resulting from a haptotactic or a chemotactic stimulus was measured in Transwell ${ }^{\circledR}$ cell culture chambers (Costar, Milano, Italy). In the haptotaxis assay the lower surface of a polyvinylpyrrolidone-free polycarbonate filter $(8-\mu \mathrm{m}$ pore size) was coated with $10 \mu \mathrm{g} / \mathrm{ml}$ fibronectin and left in a humidified cell culture chamber at $37^{\circ} \mathrm{C}$ for $2 \mathrm{~h}$, then washed with CMF-DPBS before cell seeding. In the chemotaxis assay, inserts were used without coating. Cells were treated for $1 \mathrm{~h}$ with RAPTA-T $10^{-4} \mathrm{M}$ in DPBS. After treatment cells were removed with a trypsinEDTA solution, collected by centrifugation, re-suspended in serum-starved medium supplemented with $0.1 \% \mathrm{w} / \mathrm{v}$ BSA and $1 \times 10^{5}$ cells in $0.2 \mathrm{ml}$ were sown in the upper compartment of each chamber. The lower compartment was filled with serum-starved medium supplemented with $0.1 \% \mathrm{w} / \mathrm{v}$ BSA and with complete medium for the haptotaxis and the chemotaxis assay, respectively.

Cells were left to migrate for $24 \mathrm{~h}$, then the cells on the upper surface of the filters were removed with a cotton swab and migrating cells, present in the lower surface, were detected by the crystal violet assay.

Invasion assay. Invasive ability was measured in a Transwell cell culture chamber according to the method of Albini et al (16). Briefly, the upper surface of the polycarbonate filter (8- $\mu \mathrm{m}$ pore size) of Transwell cell culture chambers was coated with $50 \mu \mathrm{l}$ of a $600 \mu \mathrm{g} / \mathrm{ml}$ Matrigel solution and air dried overnight at room temperature. The filters were reconstituted with DMEM medium for 90 min under gently shaking immediately before use. Cells were treated as described for the migration assays and $0.5 \times 10^{5}$ cells in $0.2 \mathrm{ml}$ were sown in each chamber. Cells were left to invade for $96 \mathrm{~h}$, then the cells on the upper surface of the filters were removed with a cotton swab and invading cells, present in the lower surface, were detected by the crystal violet assay.

Crystal violet assay. The crystal violet assay was performed according to the method described by Kueng et al (17). Briefly, the cells present on the lower surface of the filter were fixed with a $1.1 \% \mathrm{w} / \mathrm{v}$ glutaraldehyde solution for $15 \mathrm{~min}$. After fixation the wells were washed three times with distilled water and air dried. Cells were stained for $20 \mathrm{~min}$ with $0.1 \% \mathrm{w} / \mathrm{v}$ crystal violet prepared in $200 \mathrm{mM}$ boric acid, $\mathrm{pH}$ 9.0, then washed three times with distilled water and air-dried prior to dissolve the dye with $10 \%$ acetic acid solution. The optical density was read at $590 \mathrm{~nm}$ with an automatic computerised spectrophotometer (SpectraCount).

Cell viability. To evaluate if treatment with RAPTA-T, in the experimental conditions adopted, can affect cell viability cells were treated as described above for migration tests, except they were seeded on 96-well plates. After $24 \mathrm{~h}$, the cell viability was measured by the MTT assay: a solution of MTT [3-(4,5-dimethylthiazol-2-yl)-2,5-diphenyltetrazolium bromide] dissolved in CMF-DPBS $(5 \mathrm{mg} / \mathrm{ml})$ was added to each well (10 $\mu 1$ per $100 \mu \mathrm{l}$ of medium) and the plates were incubated at $37^{\circ} \mathrm{C}$ with $5 \% \mathrm{CO}_{2}$ and $100 \%$ relative humidity for $4 \mathrm{~h}$. After this time, the medium was discarded and $200 \mu \mathrm{l}$ of DMSO was added to each well to dissolve the formazan crystals (18). The optical density was measured at $570 \mathrm{~nm}$ with an automatic computerised spectrophotometer (Spectra Count).

Zymography. To visualise the direct effect of RAPTA-T on the activity and/or production of MMP-2 and MMP-9 enzymes, sodium dodecyl sulphate (SDS) polyacrylamide gel electrophoresis (PAGE) zymography was carried out with conditioned medium of MDA-MB-231 and HBL-100 cells. Cells at 70\% confluence were incubated for $24 \mathrm{~h}$ in serum-starved medium containing $0.1 \%$ BSA, before being treated with RAPTA-T $10^{-4} \mathrm{M}$ for $1 \mathrm{~h}$. At the end of the treatment, the RAPTA-T solution was discarded and complete serum-free medium containing $0.1 \%$ BSA was added for a further $24 \mathrm{~h}$, when culture media were collected, centrifuged to remove cellular debris, then concentrated $\sim 15$ times using Amicon ${ }^{\circledR}$ Ultra-15 30,000 nominal molecular weight limit centrifugal filter devices (Millipore Corporation, Bedford, MA). The conditioned media obtained were stored at $-80^{\circ} \mathrm{C}$ until use. Equal amounts of proteins, as determined by the Bradford method (19), for each sample were eluted with Laemmli nonreducing sample buffer and analysed by SDS-PAGE on a 7\% polyacrylamide gel containing $0.1 \%(\mathrm{w} / \mathrm{v})$ gelatine. At the end of electrophoresis in a dual-laboratory system (Protean II, Bio-Rad Laboratories, Hercules, CA), the gels were washed two times for $30 \mathrm{~min}$ at $4^{\circ} \mathrm{C}$ in $2.5 \%$ Triton $\mathrm{X}-100$ to remove SDS. After additional washing in water (three times for $5 \mathrm{~min}$ ), the gels were incubated at $37^{\circ} \mathrm{C}$ overnight in collagenase buffer [200 mM NaCl, $50 \mathrm{mM}$ tris(hydroxymethyl) aminomethane, $5 \mathrm{mM} \mathrm{CaCl}_{2}$, adjusted to $\mathrm{pH} 7.4$ ] to reactivate enzyme activity. The gels were then stained with $0.5 \%$ Coomassie brilliant blue. The gelatinolytic regions were observed as white bands against a blue background. Quantitative evaluation of the band intensity, on the basis of grey levels, was performed using Image Master 2D version 4.01 and Magic Scan 32 version 4.3 software.

In vivo tests. The in vivo experiments were carried out with the murine mammary carcinoma (MCa), originally obtained from the Department of Biology, Rudjer Boskovich Institute (Zagreb, Croatia), grown in CBA female mice (20), obtained from a local breeding colony grown according to the standard procedures for inbred strains. The tumour line was locally maintained by serial biweekly passages of $10^{6}$ viable tumour cells, of a cell suspension prepared from mincing (with scissors) the primary tumour masses obtained from donors 


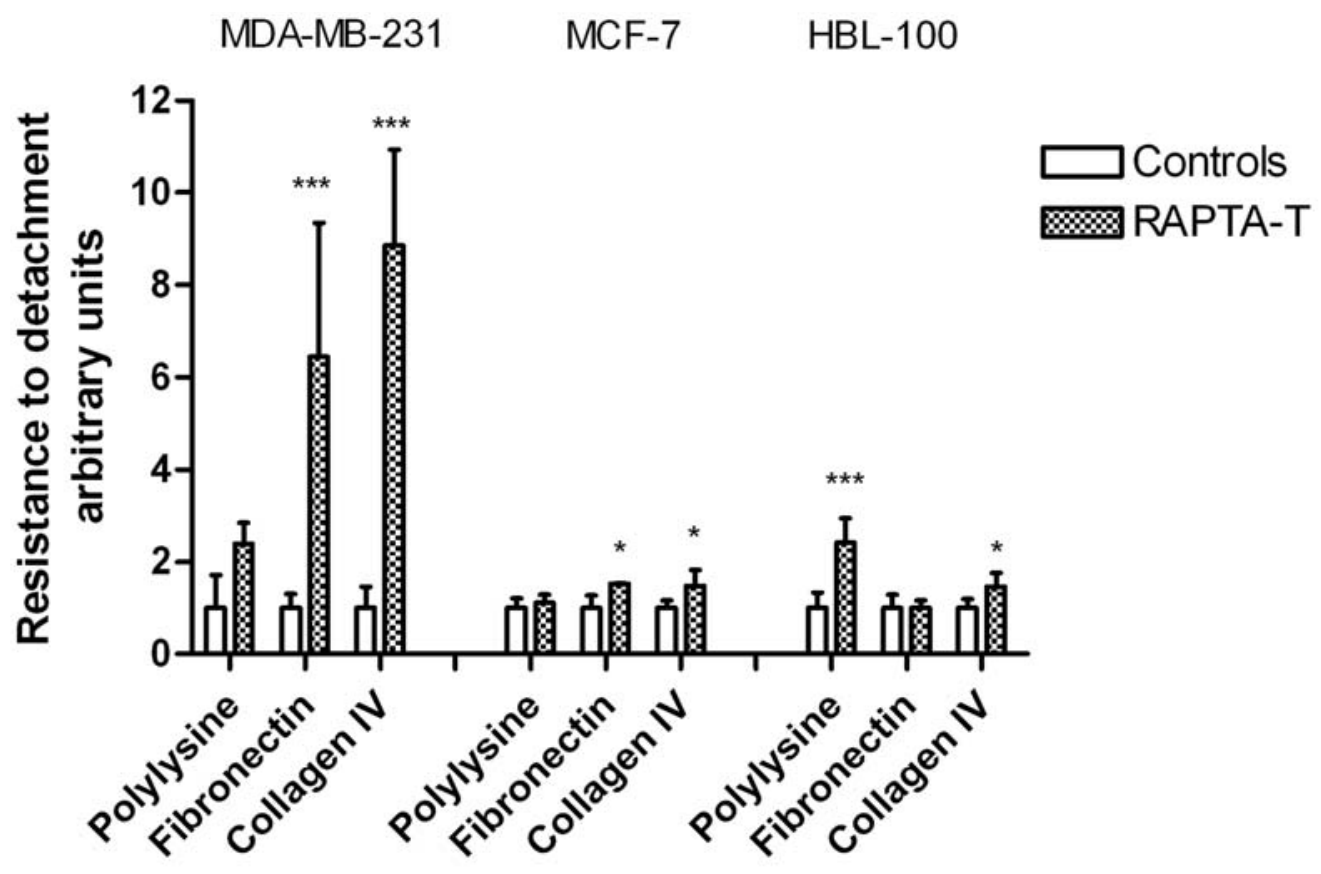

Figure 2. Effect of RAPTA-T on resistance to detachment. MDA-MB-231, MCF-7 and HBL-100 cells seeded on 96-well plastic plates previously coated with polylysine, fibronectin and collagen IV, exposed for $1 \mathrm{~h}$ to RAPTA-T $10^{-4} \mathrm{M}$ and then to a diluted trypsin solution for $30 \mathrm{~min}$, before detecting cells still attached to the growth substrate by the SRB test. Arbitrary units are calculated from the mean $\pm \mathrm{SD}$ of two experiments, each performed in quadruplicate. ${ }^{*} \mathrm{P}<0.05 ;{ }^{* *} \mathrm{p}<0.01$; ${ }^{* * *} \mathrm{p}<0.001$ vs. controls, ANOVA and Tukey-Kramer post test.

similarly implanted 2 weeks before. The minced tissue was filtered through a double layer of sterile gauze, centrifuged at $250 \mathrm{x}$ g for $10 \mathrm{~min}$ and re-suspended in an equal volume of CMF-DPBS; viable cells were counted by the trypan blue exclusion test. Viable tumour cells $\left(10^{6}\right)$ were injected i.m. into the left hind calf of experimental groups. RAPTA-T was dissolved in physiological saline $(0.9 \% \mathrm{NaCl})$ and given to mice by i.p. (intra peritoneal) administrations of $80 \mathrm{mg} / \mathrm{kg} /$ day on days 8,9 and 12 after tumour implant.

Primary tumour growth was determined by calliper measurements, by measuring two orthogonal axes and the tumour volume was calculated with the formula: (П/6) $\mathrm{xa}^{2} \mathrm{xb}$, where $\mathrm{a}$ is the shorter axis and $\mathrm{b}$ the longer axis, assuming tumour density equal to $1 \mathrm{~g} / \mathrm{ml}$. The evaluation of the number and weight of lung metastases was performed by examining the surface of the lungs immediately after sacrificing the animals by cervical dislocation. Lungs were dissected into five lobes, washed with CMF-DPBS and examined under a low power microscope equipped with a calibrated grid. The weight of each metastasis was calculated by applying the same formula used for primary tumours and the sum of each individual weight gave the total weight of metastatic tumour per animal.

Animal studies. Animal studies were carried out according to guidelines enforced in Italy (DDL 116 of 21/2/1992 and subsequent addenda) and in compliance with the Guide for the Care and Use of Laboratory Animals (Department of Health and Human Services Publ. No. 86-23, Bethesda, MD, NIH, 1985).

Statistical analysis. Results were subjected to computerassisted statistical analysis using the one-way analysis of variance ANOVA and the Tukey-Kramer post-test. Differences of $\mathrm{p}<0.05$ were considered to be significantly different from the controls.

\section{Results}

The effects of RAPTA-T treatment were studied using three cell lines coming from the mammary epithelium, characterized by different degrees of malignancy (MDA-MB-231 > MCF-7 $>$ HBL-100).

Resistance to detachment. When seeded on different Extra Cellular Matrix (ECM) components, or on poly-L-lysine as a control substrate, $1 \mathrm{~h}$ treatment with $10^{-4} \mathrm{M}$ RAPTA-T of the highly invasive MDA-MB-231 cells leads to an 8-fold statistically significantly increase of the number of cells that remained adherent to fibronectin or collagen IV after $30 \mathrm{~min}$ exposure to a very diluted trypsin solution (Fig. 2). On the non-specific substrate poly-L-lysine, RAPTA-T was unable to induce the same effect. Also, no such effects are detected on MCF-7, tumourigenic but not invasive cells and on HBL-100, non-tumourigenic cells, in response to RAPTA-T.

Re-adhesion after treatment. The effects on cell ability to re-adhere after RAPTA-T treatment were studied exposing cells to the compound while they were adherent to the growth substrate.

Under these conditions MDA-MB-231 cells, after treatment, are not more able to adhere to proteins of ECM (e.g. fibronectin, collagen IV or Matrigel), or to the nonspecific substrate poly-L-lysine. The reduction of adhesion is quantitatively comparable in all the reported substrates. The prolongation of the time allowed for adhesion, from $30 \mathrm{~min}$ to 


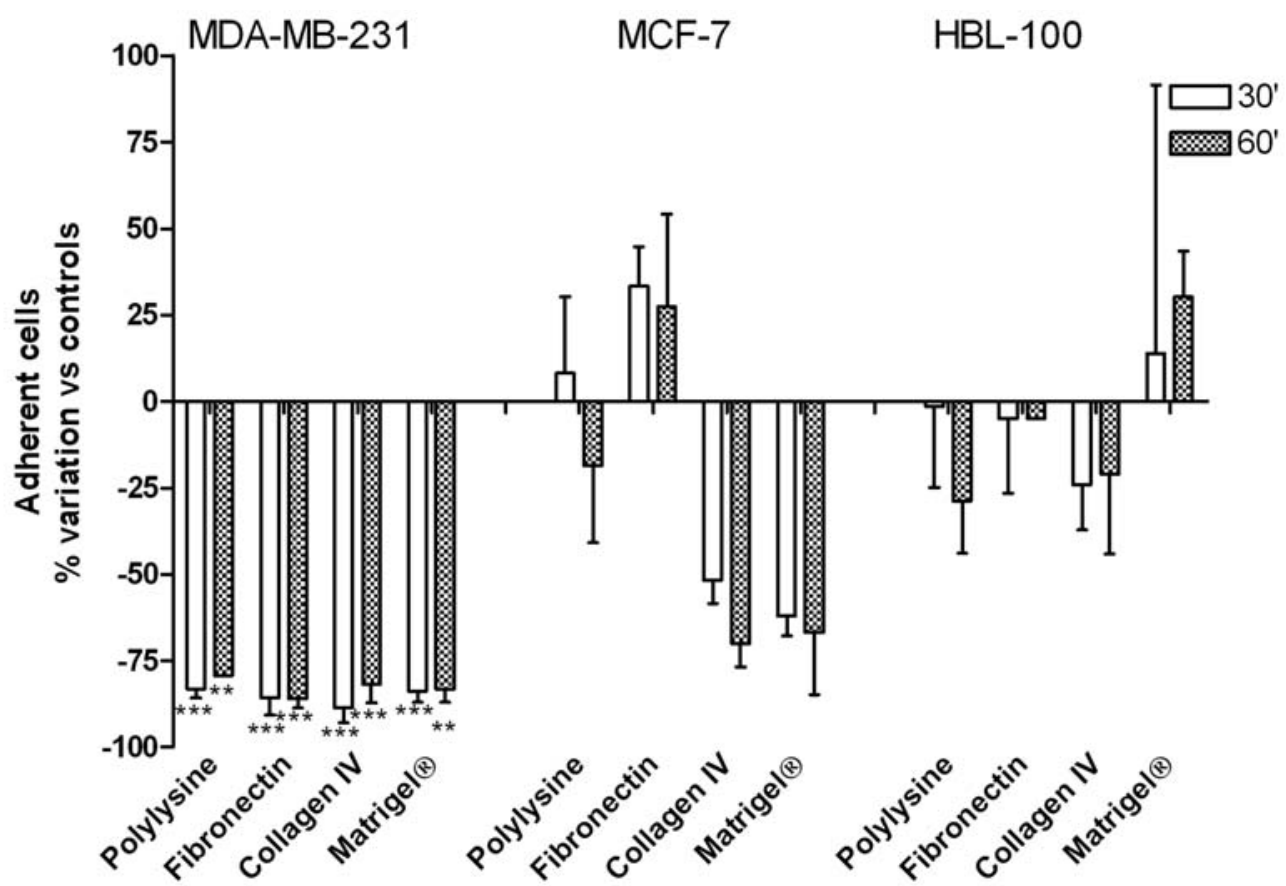

Figure 3. Effect on ability of cells to re-adhere after RAPTA-T treatment. MDA-MB-231, MCF-7 and HBL-100 cells were treated for $1 \mathrm{~h}$ with RAPTA-T $10^{-4} \mathrm{M}$, then the cells were removed from the flasks, collected, re-suspended and seeded on 96-well plastic plates previously coated with polylysine, fibronectin, collagen IV and Matrigel. After 30 and 60 min of incubation cells that adhered to the substrates were detected by the SRB test. Data are the percent of variation vs. controls calculated from the mean $\pm \mathrm{SD}$ of two experiments, each performed in triplicate. ${ }^{* *} \mathrm{P}<0.01 ;{ }^{* * *} \mathrm{p}<0.001$ vs. controls, ANOVA and Tukey-Kramer post test.

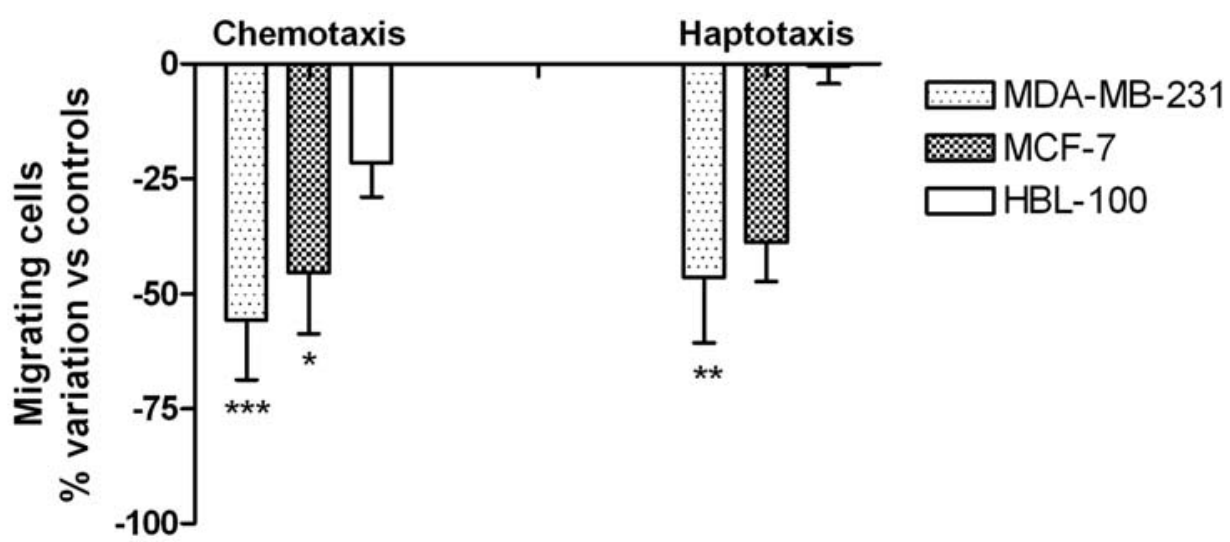

Figure 4. Effect of RAPTA-T on migration of cells through polycarbonate filters. MDA-MB-231, MCF-7 and HBL-100 cells were treated for 1 h with RAPTA-T $10^{-4} \mathrm{M}$, then the cells were removed from the flasks, collected, re-suspended and seeded on the inserts of Transwell cell culture chambers. Data represent cells that after $24 \mathrm{~h}$ have migrated and are present on the lower surface of the filter. Data are the percent of variation vs. controls calculated from the mean $\pm \mathrm{SD}$ of two experiments each performed in triplicate. ${ }^{*} \mathrm{P}<0.05 ;{ }^{* *} \mathrm{p}<0.01 ;{ }^{* * *} \mathrm{p}<0.001 \mathrm{vs}$. controls, ANOVA and Tukey-Kramer post test.

$60 \mathrm{~min}$, does not increase the number of treated cells ability to adhere (Fig. 3). Under the same experimental conditions RAPTA-T does not alter the ability of HBL-100 cells to readhere, in comparison to untreated controls and reduces the tendency to adhere to collagen IV and to Matrigel of MCF-7treated cells, although this trend is not statistically significant.

Effects on migration and invasion. The influence of RAPTA-T on the migration process of the three test cell lines is qualitatively similar when a chemical (chemotaxis) or a contact (haptotaxis) stimulus is applied to promote cell movement (Fig. 4). In both cases, the greatest inhibition is achieved with MDA-MB-231 cells that reduce, in a statistically significant manner, their migration ability to $\sim 50 \%$ of controls. MCF-7 cells also show a reduced migratory ability, although this effect is not always significant, whereas HBL-100 maintain, practically unaltered, their movement properties. A similar trend is found also in the invasion test: the invasive ability of MDA-MB-231 cells is reduced by $\sim 50 \%$, whereas it is only slightly affected with MCF-7 cells and it remains unaltered in HBL-100 cells (Fig. 5).

Effect on cell viability. To exclude the interference of RAPTA-T on cell viability on the cell invasion and migration processes an MTT test was performed using the same experimental conditions adopted in the functional assays 


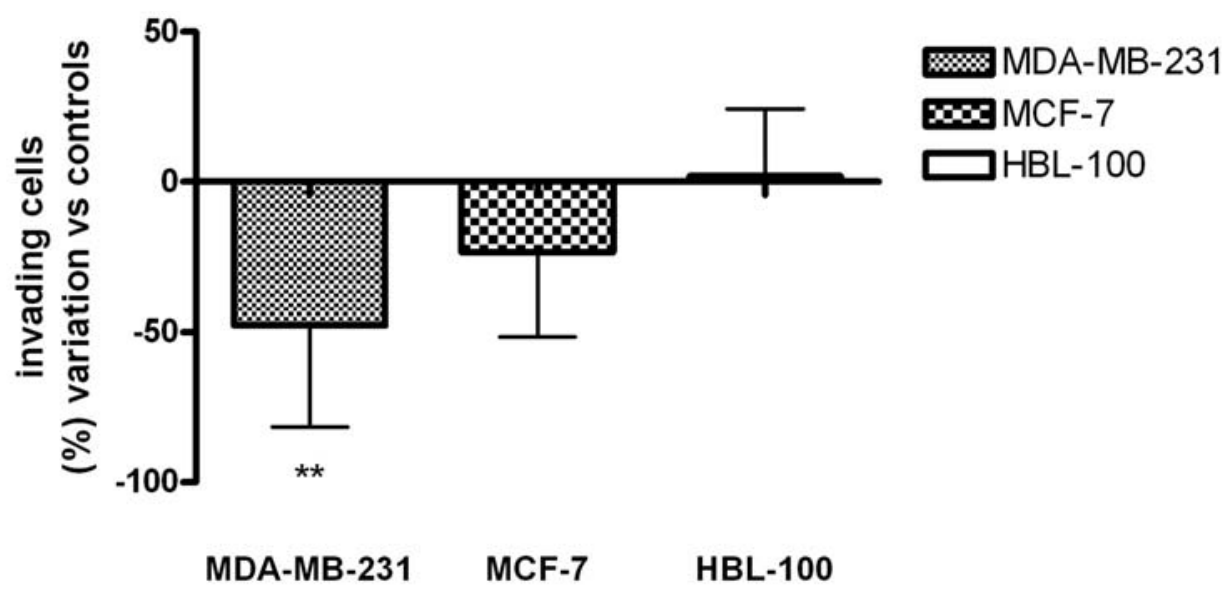

Figure 5. Effect of RAPTA-T on invasion of cells through Matrigel ${ }^{\circledR}$. MDA-MB-231, MCF-7 and HBL-100 cells were treated for $1 \mathrm{~h}$ with RAPTA-T $10^{-4} \mathrm{M}$, then the cells were removed from the flasks, collected, re-suspended and seeded on inserts. Data represent cells that after $96 \mathrm{~h}$ have invaded and are present on the lower surface of the filter. Data are the percent of variation vs. controls calculated from the mean \pm SD of two experiments, each performed in triplicate. ${ }^{* *} \mathrm{P}<0.01$; vs. controls, ANOVA and Tukey-Kramer post test.

Table I. Effect of RAPTA-T on cell viability.

\begin{tabular}{lccc}
\hline & MDA-MB-231 & MCF-7 & HBL-100 \\
\hline Controls & $2.276 \pm 0.071$ & $2.412 \pm 0.150$ & $2.483 \pm 0.199$ \\
RAPTA-T & $2.596 \pm 0.070$ & $2.478 \pm 0.130$ & $2.061 \pm 0.151$ \\
& $(114 \%)$ & $(103 \%)$ & $(83.0 \%)$ \\
\hline
\end{tabular}

MDA-MB-231, MCF-7 and HBL-100 cells were treated for $1 \mathrm{~h}$ with RAPTA-T $10^{-4} \mathrm{M}$, then the cells were removed from the flasks, collected, re-suspended and seeded on 96-well plates. After $24 \mathrm{~h}$, cell viability was determined by the MTT assay. Data are the mean optical density \pm SD of two experiments each performed in quadruplicate. Data in parentheses represent the percentage of each treated group vs. the relevant controls $(\mathrm{T} / \mathrm{C} \%)$.

Table II. Effect of RAPTA-T on lung metastases formation in mice with MCa mammary carcinoma.

\begin{tabular}{lccccc}
\hline & \multicolumn{2}{c}{ Primary tumour weight $(\mathrm{mg})$} & & \multicolumn{2}{c}{ Lung metastases $^{\mathrm{a}}$} \\
\cline { 5 - 6 } & Day 13 & Day 20 & & Number & Weight (mg) \\
\hline Controls & $884 \pm 202$ & $2455 \pm 376$ & & $24.4 \pm 15.8$ & $8.99 \pm 6.50$ \\
RAPTA-T & $682 \pm 170$ & $2443 \pm 389$ & & $19.4 \pm 11.9$ & $3.19 \pm 4.10$ \\
& $(77.1 \%)$ & $(99.5 \%)$ & & $(79.5 \%)$ & $(35.5 \%)$ \\
\hline
\end{tabular}

Groups of 9 CBA mice, inoculated i.m. with $10^{6} \mathrm{MCa}$ tumour cells on day 0 were treated i.p. with RAPTA-T at $80 \mathrm{mg} / \mathrm{kg} /$ day on days 8 , 9 and 12 after tumour implant. Data in parentheses are expressed as the percentage of the treated vs. controls (T/C \%). ${ }^{\text {LL Lung metastases }}$ were determined on day 20 after tumour implant.

(Table I). Cell viability, $24 \mathrm{~h}$ after the $1 \mathrm{~h}$ treatment with RAPTA-T, shows that the ruthenium compound induces only slight and non-significant oscillations $( \pm 10 \%$ depending on the cell line being treated) as compared to the relevant controls.
Effect on MMPs production and activity. The effect of RAPTA-T on the matrix metalloproteinases (MMPs) production and/or activity was studied by a gelatine zymography test (Fig. 6). MDA-MB-231 cells produce the 92 kDa MMP-9 in appreciable amounts; RAPTA-T treatment statistically reduces the production/activity of this gelatinase by $\sim 30 \%$ vs. controls. In the conditioned medium harvested from HBL-100 cells, on which both the $92 \mathrm{kDa}$ MMP-9 and the $72 \mathrm{kDa}$ MMP-2 are present, RAPTA-T treatment moderately increases the production/activity of both MMP-2 and MMP-9, although the variations are not statistically significant.

Effect on lung metastases in vivo. The effect of RAPTA-T treatment on primary tumour growth and lung metastasis formation were studied in the model of MCa mammary carcinoma, a murine transplantable tumour that spontaneously metastasise to the lungs (Table II). RAPTA-T, given at $80 \mathrm{mg} /$ $\mathrm{kg}$ /day on days 8,9 and 12 after tumour implant, only marginally affects primary tumour growth, showing the maximum effect (23\% inhibition vs. controls) on day 13 (i.e., $24 \mathrm{~h}$ after the last compound injection). The modest control of the primary tumour growth is not maintained after the end of RAPTA-T administration and it is lost on day 20. Despite the negligible reduction of the primary tumour, RAPTA-T is able to selectively counteract the development and growth of lung metastases particularly as regards the weight of these tumours that is reduced to $35 \%$ of controls. The pronounced inhibition of metastasis weight is caused by the decrease of the number of metastases of large dimensions (diameter $\geq 2 \mathrm{~mm}$ ) in the treated group where only 2 out of 8 mice showed them in comparison to 7 out of 9 mice in the control group.

\section{Discussion}

In the present study, we evaluated the interference of RAPTA-T with some steps of the metastatic progression by in vitro tests that mimic the in vivo processes, i.e. detachment, motility, invasion and the adaptation/adhesion to a new environment (21). RAPTA-T was chosen among other 


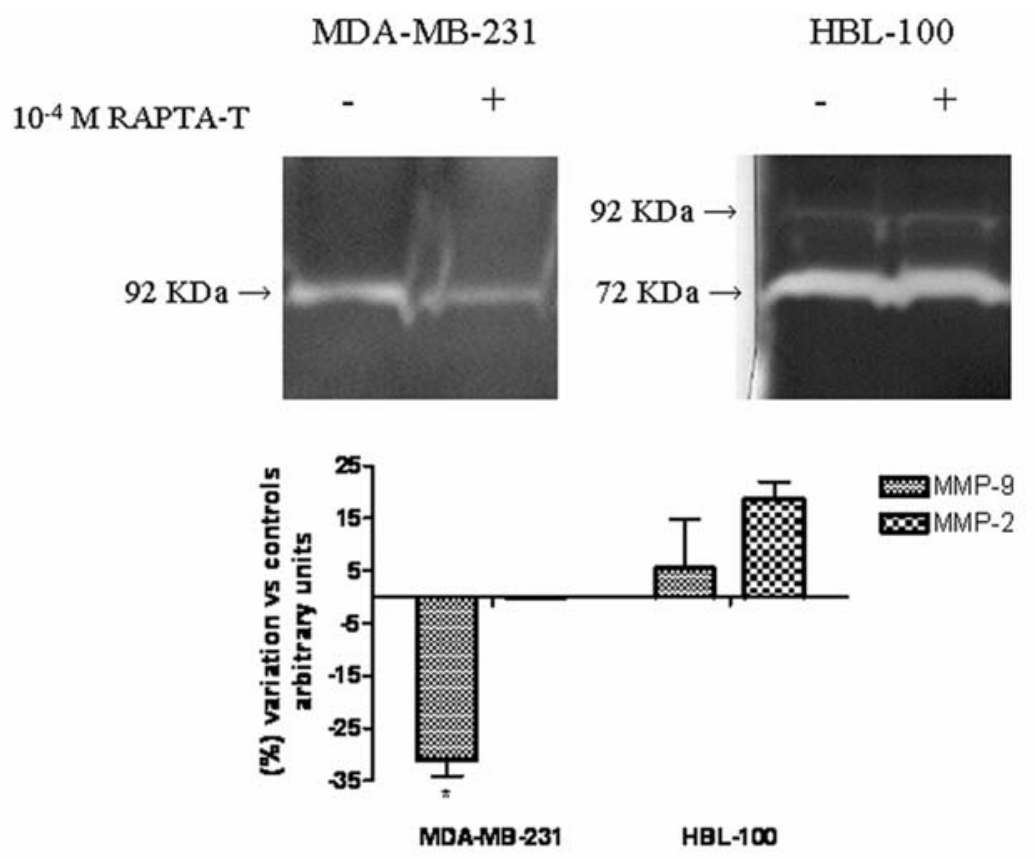

Figure 6. Effect of RAPTA-T on MMPs production and/or activity. MDA-MB-231 and HBL-100 cells were treated for $1 \mathrm{~h}$ with RAPTA-T $10^{-4} \mathrm{M}$, then incubated for an additional $24 \mathrm{~h}$ in serum-starved complete medium containing 0.1\% BSA. Supernatants containing MMPs were collected and concentrated and equal protein amounts $(100 \mu \mathrm{g})$ subjected to SDS-PAGE. Gelatine digestion by proteases is detected as white bands against a blue background (upper panel). Band digestion is quantified by using Image Master 2D version 4.01 and Magic Scan 32 version 4.3 software (lower panel). ${ }^{*} \mathrm{P}<0.05$; vs. controls, ANOVA and Tukey-Kramer post test.

members of the RAPTA family, because of its selective cytotoxicity against the TS/A adenocarcinoma cells $\left(\mathrm{IC}_{50}=74 \mu \mathrm{M}\right.$, $72 \mathrm{~h}$ ), whereas it is essentially non-toxic to the HBL-100 non-tumourigenic cells (no cytotoxicity observed at the maximum dose of $300 \mu \mathrm{M}$ ) under analogous conditions (14). In the functional tests adopted in our experimental protocol, RAPTA-T also shows a clear cell type specificity, characterized by a more pronounced effect on tumour cells, rather than on the non-tumourigenic HBL-100. Moreover, these effects are stronger when the highly invasive MDA-MB-231 cells are used, in comparison to MCF-7 non-invasive cells. It would seem therefore, that RAPTA-T is able to interfere more selectively with tumour cells with the highest inclination to invade and metastasise. Moreover, it should be considered that RAPTA-T displays such properties in a series of tests chosen and designed to highlight activities in one or more steps of the metastatic progression (22). The higher activity of RAPTA-T towards the invasive MDA-MB-231 is a common trait, although quantitatively different as a function of the experiment type. In particular, the ruthenium compound has the greatest effect on cell detachment from, and on cell re-adhesion on growth substrates, two tests that would mimic the de-adhesion of the tumour cells from the primary site of growth and the adhesion to a new organ of cells that begin the metastatic colonization, after surviving the stresses of the bloodstream. In the detachment assay, after treatment of MDA-MB-231 cells with RAPTA-T the cells remain much more attached to the substrate, 7-9-fold in comparison to control cells, when they are seeded on proteins of the extracellular matrix such as fibronectin and collagen IV, but not when cells grow on poly-L-lysine, a substrate on which cells adhere by electrostatic interactions only (23). On the contrary, in the re-adhesion test RAPTA-T prevents the adhesion of treated cells on all the used substrates exactly to the same extent. The effects found in the detachment test and in the re-adhesion test could be caused by the same modification induced by RAPTA-T and consisting in a stiffening of the cell body, that results in the loss of the plasticity required both for the detachment and for the readhesion processes. In both these assays the effects, similarly investigated, on MCF-7 or HBL-100 are virtually negligible or less pronounced. The same cell specificity emerges in the migration/invasion tests, in which MDA-MB-231 is the only cell line that is always inhibited, in a statistically significant manner, in both chemotaxis and haptotaxis, as well as in the invasion tests. These results also support the hypothesis that the modulation of the cytoskeleton is involved in RAPTA-T activity, that is the loss of cell body plasticity that hampers cell detachment and re-adhesion, also prevents cell motility, a cyclic repetition of these two processes (24). It is worth noting that the reduction of migrating MDA-MB-231 cells is always $50 \%$, irrespectively of the type of the applied stimulus, chemical in chemotaxis or associated to the extracellular matrix as in haptotaxis, as if the role of this component is not relevant. Moreover, in the invasion test the reduction caused by RAPTA-T is also 50\% indicating that the presence of the Matrigel barrier to be digested is indifferent to RAPTA-Ttreated cells. The zymography confirms the independence of the invasion inhibition from the down-regulation of the MMPs activity and/or production. Again the results are cell linedependent in that MMP-9 production and/or activity by MDA-MB-231 cells is reduced by RAPTA-T, whereas the same protein is not affected if it comes from HBL-100 subjected to analogous conditions, neither is the production 
and/or activation of MMP-2, also present in the supernatant of this cell line. Although the reduction of MMP-9 in MDAMB-231 is probably not strong enough to have a biological significance, the fact that it is affected by RAPTA-T treatment, otherwise MMP-9 in HBL-100, allows us to hypothesise the ruthenium compound acts on a target expressed by the highly invasive cells, but not shared by the non-tumourigenic ones. Moreover, this target is not related to a conventional cytotoxic mechanism as highlighted by the lack of significant variations of cell growth in the adopted experimental conditions. The propensity of RAPTA-T to interfere with cells endowed with invasive ability is suggested from the in vivo experiments, where despite a negligible reduction of the primary tumour growth it interferes with the growth of lung metastases. The analysis of the anti-metastatic effects points out a reduction of the weight, probably due to the reduction of metastases of large dimensions. On a pure speculative basis, we might suppose that the in vivo effect reflects a fast pharmacokinetics of RAPTA-T which is released from the target and eliminated from the body rapidly after drug withdrawal. Then, metastasis formation is inhibited only during drug treatment and the overall effect is affected by those formed after the end of the treatment. Anyhow, it should be said that this result puts RAPTA-T among the substances of great therapeutic impact, given that metastasis growth is considered the most promising stage of the metastasis process for therapeutic intervention $(25,26)$.

The in vivo selective anti-metastatic activity displayed by RAPTA-T might be justified by the in vitro activity, particularly relevant on the highly invasive cells and in the detachment- and adhesion-tests, both requiring the interaction of the tumour cells with extra cellular matrix components and suggests the involvement of cell surface molecules in the activity of this ruthenium compound.

It is worth noting that RAPTA-T is unlikely to be the most active/effective compound in the RAPTA family. Based on these experiments it is now possible to screen compounds for antimetastatic activity prior to testing the compounds in vivo. This screening protocol is particularly important as NAMI-A and most RAPTA compounds are only weakly active in traditional in vitro cytotoxicity studies and would not normally be considered for in vivo studies, although the correlation with in vivo antimetastatic activity is poor. The correlation between our in vitro findings and the in vivo anti-metastatic activity is in good agreement with similar results reporting Salvicine as a selectively anti-metastatic substance, able to affect the integrin-mediated tumour cell adhesion $(27,28)$. These data point out that the search of new targets, unrelated to the DNA interactions that drove medicinal metal-based research in the past decades $(29,30)$ can provide new tools for therapy and significant clinical advancements.

\section{Acknowledgements}

Fondazione CRTrieste (project 'MADE') and Regione Autonoma Friuli Venezia Giulia (project 'Nuove Terapie e Farmaci Antitumorali') are gratefully acknowledged for financial support. This study was performed within the frame of COST Action D39.

\section{References}

1. Wang E and Giandomenico CM: Current status of platinum-based antitumor drugs. Chem Rev 99: 2451-2466, 1999.

2. Wang D and Lippard SJ: Cellular processing of platinum anticancer drugs. Nat Rev Drug Discov 4: 307-320, 2005.

3. Kostova I: Ruthenium complexes as anticancer agents. Curr Med Chem 13: 1085-1107, 2006.

4. Galanski M, Arion VB, Jakupec MA and Keppler BK: Recent developments in the field of tumor-inhibiting metal complexes. Curr Pharm Des 9: 2078-2089, 2003.

5. Dyson PJ and Sava G: Metal-based antitumour drugs in the post genomic era. Dalton Trans 1929-1933, 2006.

6. Sava G, Zorzet S, Turrin C, Vita F, Soranzo M, Zabucchi G, Cocchietto M, Bergamo A, DiGiovine S, Pezzoni G, Sartor L and Garbisa S: Dual action of NAMI-A in inhibition of solid tumor metastasis: selective targeting of metastatic cells and binding to collagen. Clin Cancer Res 9: 1898-1905, 2003.

7. Rademaker-Lakhai JM, Van den Bongard D, Pluim D, Beijnen JH and Schellens JH: A phase I and pharmacological study with imidazolium-trans-DMSO-imidazole-tetrachlororuthenate, a novel ruthenium anticancer agent. Clin Cancer Res 10: 3717-3727, 2004.

8. Sava G, Frausin F, Cocchietto M, Vita F, Podda E, Spessotto P, Furlani A, Scarcia V and Zabucchi G: Actin-dependent tumour cell adhesion after short-term exposure to the antimetastasis ruthenium complex NAMI-A. Eur J Cancer 40: 1383-1396, 2004.

9. Zorzet S, Bergamo A, Cocchietto M, Sorc A, Gava B, Alessio E, Iengo $\mathrm{E}$ and Sava G: Lack of in vitro cytotoxicity, associated to increased G2-M cell fraction and inhibition of matrigel invasion, may predict in vivo-selective antimetastasis activity of ruthenium complexes. J Pharmacol Exp Ther 295: 927-933, 2000.

10. Aird RE, Cummings J, Ritchie AA, Muir M, Morris RE, Chen H, Sadler PJ and Jodrell DI: In vitro and in vivo activity and cross resistance profiles of novel ruthenium (II) organometallic arene complexes in human ovarian cancer. Br J Cancer 94: 1652-1657, 2002.

11. Allardyce CS, Dyson PJ, Ellis DJ and Heath SL: $\left[\mathrm{Ru}\left(\eta^{6}-\mathrm{p}-\right.\right.$ cymene) $\mathrm{Cl}_{2}$ (pta)] (pta = 1,3,5-triaza-7-phosphatricyclo-[3.3.1.1] decane): a water soluble compound that exhibits $\mathrm{pH}$ dependent DNA binding providing selectivity for diseased cells. Chem Commun 15: 1396-1397, 2001

12. Allardyce CS, Dyson PJ, Ellis DJ, Salter PA and Scopelliti R: Synthesis and characterization of some water soluble ruthenium (II)-arene complexes and an investigation of their antibiotic and antiviral properties. J Organomet Chem 668: 35-42, 2003.

13. Scolaro C, Geldbach TJ, Rochat S, Dorcier A, Gossens C, Bergamo A, Cocchietto M, Tavernelli I, Sava G, Rothlisberger U and Dyson PJ: Influence of Hydrogen-bonding substituents on the cytotoxicity of RAPTA compounds. Organometallics 25: 756-765, 2006.

14. Scolaro C, Bergamo A, Brescacin L, Delfino R, Cocchietto M, Laurenczy G, Geldbach TJ, Sava G and Dyson PJ: In vitro and in vivo evaluation of ruthenium(II)-arene PTA complexes. J Med Chem 48: 4161-4171, 2005.

15. Skehan P, Soreng R, Scudiero D, Monks A, McMahon J, Vistica D, Warren JT, Bokesch H, Kenney S and Boyd MR: New colorimetric cytotoxicity assay for anticancer-drug screening. J Natl Cancer Inst 82: 1107-1112, 1990.

16. Albini A, Iwamoto Y, Kleinman K, Martin GR, Aaronson SA, Kozlowski JM and McEwan RN: A rapid in vitro assay for quantitating the invasive potential of tumour cells. Cancer Res 47: 3239-3245, 1987

17. Kueng W, Silber E and Eppenberger U: Quantification of cells cultured on 96-well plates. Anal Biochem 182: 16-19, 1989.

18. Alley MC, Scudiero DA, Monks A, Hursey ML, Czerwinski MJ, Fine DL, Abbott BJ, mayo JG and Shoemaker RH: Feasibility of drug screening with panels of human tumor cell lines using a microculture tetrazolium assay. Cancer Res 48: 589-601, 1988.

19. Bradford MM: A rapid and sensitive method of the quantitation of microgram quantities of protein utilising the principle of protein-dye binding. Anal Biochem 72: 248-254, 1976.

20. Poliak-Blazi M, Boranic M, Marzan R and Radacic MA: A tranplantable aplastic mammary carcinoma of CBA mice. Vet Arch 15: 99-107, 1981.

21. Fidler IJ: The pathogenesis of cancer metastasis: the 'seed and soil' hypothesis revisited. Nat Rev Cancer 3: 453-458, 2003.

22. Eccles SA, Box C and Court W: Cell migration/invasion assays and their application in cancer drug discovery. Biotechnol Annu Rev 11: 391-421, 2005. 
23. Elbert DL and Hubbel JA: Reduction of fibrous adhesion formation by a copolymer possessing affinity for anionic surfaces. J Biomed Mater Res 42: 55-65, 1998.

24. Ridley AJ, Schwartz MA, Burridge K, Firtel RA, Ginsberg MH, Borisy G, Parsons JT and Horwitz AR: Cell migration: integrating signals from front to back. Science 302: 1704-1709, 2003.

25. Chambers AF, MacDonald IC, Schmidt EE, Morris VL and Groom AC: Clinical targets for anti-metastasis therapy. Adv Cancer Res 79: 91-121, 2000.

26. Hedley BD, Winquist E and Chambers AF: Therapeutic targets for antimetastatic therapy. Expert Opin Ther Targets 8: 527-536, 2004.

27. Lang JY, Chen H, Zhou J, Zhang YX, Zhang XW, Li Mh, Lin LP, Zhang JS, Waalkes MP and Ding J: Antimetastatic effect of salvicine on human breast cancer MDA-MB-435 orthotopic xenograft is closely related to Rho-dependent pathway. Clin Cancer Res 11: 3455-3464, 2005.
28. Zhou J, Chen Y, Lang JY, Lu JJ and Ding J: Salvicine inactivates beta 1 integrin and inhibits adhesion of MDA-MB-435 cells to fibronectin via reactive oxygen species signalling. Mol Cancer Res 6: 194-204, 2008.

29. Brabec V and Novakova O: DNA binding mode of ruthenium complexes and relationship to tumor cell toxicity. Drug Resist Updat 9: 111-122, 2006.

30. Reedijk J: New clues for platinum antitumor chemistry: kinetically controlled metal binding to DNA. Proc Natl Acad Sci USA 100: 3611-3616, 2003. 